\title{
Pedagogical Support for Blended Learning Classrooms: Interfacing Teacher and Student Perspectives
}

\author{
Jarrent R. Tayag \\ College of Education, Angeles University Foundation, Philippines
}

Received March 23, 2020; Revised April 9, 2020; Accepted April 27, 2020

Copyright $\bigcirc 2020$ by authors, all rights reserved. Authors agree that this article remains permanently open access under the terms of the Creative Commons Attribution License 4.0 International License

\begin{abstract}
The continued rise of technology in the educational system has brought about new teaching approaches such as blended learning. To fully utilize this approach, researchers have focused on studying the dynamics between various learning variables and its implementation. However, the intersection of context in the actual implementation of blended learning in the classroom remains to be a rich field for researchers. The present study explored the pedagogical support needed to implement blended learning. By examining the perspectives of five teachers and 60 secondary students through a questionnaire and semi-structured interview, emerging themes were identified through qualitative analysis. Results revealed that students look into the alignment between the face-to-face and online instruction, proper spacing of activities, and provision of pre-requisite skills for the tasks assigned to them. While students acknowledge the benefits of using blended learning in the lesson, it is equally crucial that the challenges are resolved so they may be able to comply with the requirements set by the teachers. Teachers, on the other hand, seek the provision of technical skills, training on new pedagogies, and sufficient preparation time for them to effectively develop lessons following a blended learning approach model. With the varied degree of implementation of blended learning in schools, it is necessary for school heads and teachers to work together to develop relevant and responsive policies to support students in complying with the requirements of their classes.
\end{abstract}

Keywords Blended Learning, Pedagogical Support, Educational Technology

\section{Introduction}

Technology has paved the way for many educational reforms and innovations. With increasing pace of development in instructional technology, schools have been actively synching their curriculum to ensure that teachers and students optimize the potentials of technology in the classroom and even outside the bounds of the campus. The prominence of learning management systems (LMS) and massive open online courses (MOOCs) are but a few of the landmarks of modern education, which offers flexibility and control toward student learning. School heads and district supervisors are also spearheading partnerships with tech companies to equip their schools with advanced tools and enable them to deliver instruction in various modes.

While online learning may be gaining support in the past decades, the structured face-to-face education conducted in schools still remain to be the prevailing system for instruction. In this setup, students attend their classes while the teacher supervises them within the school grounds. Such structure has been enriched by the active inclusion and integration of technology like the use of presentation slides, computer simulations, and incorporation of technology-enhanced student tasks like webpage designing. Further developments included the production of online materials by teachers that are made accessible for students.

Blended learning is defined as form of learning that utilizes both online and face-to-face instruction [1]. Commonly referred to as a hybrid design, blended learning still follows a formal education program provided by a school. The most notable feature is the addition of online learning to enhance face-to-face instruction. Several models have been described to classify the different practices that teachers use. For instance, in flipped classroom, one of the blended learning models, students are asked to use online learning to independently study a material, which will be used for an activity during the face-to-face instruction. In school, students perform activities relevant to the online material, which the teacher facilitates through formative assessments.

Blended learning enables the efficient integration of technology and the curriculum. However, similar to other 
teaching and learning approaches, blended learning also requires a pedagogical fit for it to be optimally utilized. This implies that teachers must be able to seamlessly find the link between their desired curricular goals and the practices that they employ. Without such fit, regardless of how sophisticated an approach is, it would prove to be impractical. The present study is an exploration of the different pedagogical supports needed by both teachers and students when employing blended learning in schools. Understanding the need for these pedagogical supports can better equip school heads with coming up with more relevant programs for their schools and teachers. Teachers can also avoid the pitfall of simply employing blended learning without gauging the readiness of their learners for such approach.

\section{Literature Review}

Blended learning has been reported as a transformative approach to modern education because of its capacity to integrate instructional technology in providing meaningful learning experiences among students [2]. One of the earliest models that pertained to the structuring of blended learning environments is Khan's Octagonal Framework [3]. This framework emphasizes the need to consider eight aspects (institutional, pedagogical, technological, interface design, ethical, resource support, management, and evaluation) in implementing blended learning at an institutional level. These, along with the ubiquitous requirement to consider curricular goals and learner developmental needs, are essential in determining whether an institution is capable of delivering blended instruction. It is highlighted in the study by Moskal, Dziuban, and Hartman that a continuous upgrading of both the faculty and institution is essential in ensuring the success of blended learning [4]. Despite this, Porter and others reported the scarcity of studies that deal with the institutional adoption of blended learning, thereby leaving the important decisions to teachers, who oftentimes have less control over the availability of school resources [12].

Blended learning can also benefit a diverse group of learners. Poon reported the suitability of blended learning approach for part-time students [6]. In this vein, George-Walker and Keefe asserted that while it may be an active argument to question by how much or often a teacher should "blend" their approaches, presenting a lesson in multiple modalities, which include online learning, is an age-old principle that must be observed by all teachers [8].

The impact of blended learning has been reported widely in literature. For instance, findings from the study of So and Brush showed that collaborative learning is possible even in a blended learning environment [5]. In fact, a sense of community can be established in a blended environment, which may rival, if not be better than, traditional face-to-face instruction [9]. A blended learning environment can also reduce dropout rates and even improve academic performance [10]. Stockwell and others reported that while face-to-face instruction for science improved the test scores of students, video assignments positively affected the satisfaction and attendance of students [13]. A meta-analysis conducted by Liu and others showed that blended learning has consistent positive effects for students in the health profession [14]. When compared with online courses, blended learning environments have more learning supports [11].

Contrary to these findings, Lynch and Dembo reported no significant relationship between self-regulatory variables and performance of undergraduate students who took courses in a blended environment [7]. Nevertheless, Kintu, Zhu, and Kagambe reported that several learning design features of blended learning can be considered as predictors of student learning outcomes [15].

\section{Materials and Methods}

\subsection{Research Design}

The study employed a qualitative description design, in which data were gathered directly from people who experienced a phenomenon under study [16]. The study was conducted in a secondary public high school in the Philippines. The teachers implemented lessons employing both face-to-face instruction and online platform. During the face-to-face sessions, the teacher facilitates discussions and individual and group activities. Group chats through social networks and emails were used in accessing materials from the teachers. These materials were used by the students to prepare for their face-to-face classes. Links to audio and video casts were also provided to supplement the discussions in the classroom. There were sessions that were conducted online in form of discussion boards and forums. The teacher provided assessments in both platforms.

\subsection{Data Sources}

Questionnaires with open ended questions relating to the experiences of teachers and students in using blended learning were answered. The questions focused on how blended learning was implemented and the challenges that they faced. To gain a deeper understanding of the responses, semi-structured interviews were also conducted with a sample of the students and teachers. The gathered responses were analyzed using an inductive process of condensing, encoding, and categorizing until themes emerged.

\subsection{Participants}

There were 60 secondary students (mean age $=15.33 ; 38 \%$ 
male and $62 \%$ female) who answered the questionnaire, from which 10 (mean age $=15.2$; 4 males and 6 females) were randomly selected for interview. The interview was carried out by phone and teleconferencing. Five teachers, handling different subjects for the student-respondents, were also interviewed. The teachers have been serving the school for at least three years $(\min =3$ years, $\max =12$ years).

\section{Results and Discussion}

Comparing the perceptions of teachers and students provides comprehensive discussion of how blended learning actually happens in their classes. Three themes documenting the concerns of both students and teachers are reported in this paper.

\subsection{Students' Perspective on the Use of Blended Learning}

\subsubsection{Alignment between Face-to-Face and Online Tasks}

Online activities such as watching film clips and documentary videos, answering worksheets, and conducting web research are among the typical tasks given by teachers to students. These activities are used as either inputs or enrichments for lessons that were covered in the classroom. One student recounted that his math teacher usually provides math drills in the form of online games to assist those who still need some practice on the lesson. Another narrated how the English teacher asked them to watch and listen to a video in which a sonnet was being recited. During the class, the teacher asked them to recite the sonnet with the correct pronunciation and intonation. Many of the students were able to successfully complete the task because they were able to hear it over and over prior to the session. Because the link to the video was given a week before the face-to-face session, students were able to download and even share it with others.

The blended learning environment proves to be a fertile ground for student and teacher interaction as the former cited the availability of their teachers during the face-to-face instruction to provide clarifications. One student noted that: "I can easily follow the lessons because the teacher gives us the materials ahead of time and we can ask questions about it even if it is not yet the assigned lesson for the day."

The alignment of the face-to-face instruction and online activities allowed the students to work at their own pace. Students who may be finding it challenging to keep up with the pace in the classroom can always use the online activities to master the competencies prior to assessment. Because the online activities are related to what is discussed in the classroom, the students are able to clarify concepts that may be having difficulty in. However, a few students noted that there are instances wherein online activities are sometimes used by teachers to catch up with lessons that they fail to deliver in the classroom. In a few instances, teachers would use the platform to provide materials and expect students to independently study them for an upcoming assessment.

"Students may do independent study, however, we would still need to have our classroom discussions because that is where we can raise questions about the material."

In terms of the alignment of tasks and assessment, the students noted the advantage of having the materials uploaded and readily available for them. Some students explained that because these materials can be downloaded and saved through their mobile devices, they can prepare for an assessment anywhere they are.

\subsubsection{Proper Spacing of Activities}

Students are required to attend the regular classes that they have with their teachers in the classroom, thus, their opportunity to do their online activities is usually after their class schedules each day. There are times wherein students have to complete three online activities after having completed several tasks during their classroom sessions. Some students admitted that in some cases, they unintentionally forget to complete a few online tasks, thereby forcing them to accomplish them in a limited time. In most cases, online activities are reinforcement tasks to assist those who may not have been able to master the competencies in the classroom. However, when online activities are becoming extensions of the class requirements, students are usually exhausted because of the already taxing activities that they have to perform in school. As a result, some students sacrifice some hours in the evening simply to comply with the requirements. Further, not all students have access to the internet. When limited time is given for the completion of an online requirement, students have to go out and find an internet shop where they can finish their work.

This issue is handled by a few teachers well as they provide access to the online materials weeks before the actual class session. Some students reported that some of their teachers routinely require them to do just one online activity every week.

\subsubsection{Provision of Pre-Requisite Skills}

It is a common notion that all students of the current generation are technologically savvy. While many may be skillful in movie and audio editing, webpage development, and even computer programming, there are also a number of students who are still struggling to do these because of the lack of prior training.

"Teachers should consider whether students are capable of using a software that could be used for the task. There are times that we have to spend long hours simply trying to watch tutorial videos on how to use the application, rather than think about how to do the project." 
The reality is that teachers sometimes assume too much that students are knowledgeable of every application or software available. While student do appreciate learning how to make use of new software, the tight deadlines puts them on a balance of either to spend time learning the software or simply ask someone to do the project for them. Because of the lack of security measures in online tasks, students are sometimes bending towards the latter for them to comply with the deadlines.

Pre-requisite skills are supposed to be part of the enabling tasks to be given by the teacher. However, in some cases, these skills are vessels, rather than part of the content of the curriculum. A language teacher may ask the students to prepare a video presentation about a story that they tackled in class. The language teacher may use the classroom time to discuss the story and its plot, but students will not expect the teacher to demonstrate to them how to make a video. Such creates a complexity on how blended learning can be used for this purpose.

\subsection{Teachers' Perspectives on the Use of Blended Learning}

\subsubsection{Provision of Technical Support}

While students clamor for the neglect on pre-requisite skills, teachers are also concerned about their level of expertise in terms of their technical abilities in navigating through different available software and applications. Most of the teachers are amenable that students are far better than they are in the use of computers and the internet. Thus, they sometimes feel that the tasks that they give do not optimally challenge the students. One of the teachers recounted an experience in which he asked the students to create a brochure using a word processing software. Upon mentioning this to the class, the students started to ask whether they can use other applications such as Photoshop. The teacher could not argue with the students because he does not have any idea whether such application may be applicable for the task. Nonetheless, he relented and was surprised to see the outputs. He felt that if had insisted on his guidelines, the students would have been restricted and not able to showcase their actual skills. This prompted the teacher to learn a few of these software and applications.

"There were instances wherein I did not even know how to share or upload my files. I had to call another teacher to assist me. In another instance, I did not know how to download a video. It was really a challenge for me.”

Some teachers have ideas on how to support students through blended learning. However, their technical skills hamper such sincere intentions. One teacher know that her students can benefit if she can prepare video tutorials using their mother tongue so that students can understand it better. She did try once but found it very challenging for her to edit the video. "I wanted to put subtitles and colorful images in the video, but I do not know how to." Such frustration is common among the teachers and hesitantly limits them to mere uploading of curated materials for their students.

\subsubsection{Training on New Pedagogies}

The rise of new teaching modalities requires an understanding of new pedagogies. Teachers are usually given seminars to update them on new available materials and strategies; however, these seminars are sometimes superficial in the sense that they revolve more on knowing what the approach is, but too little opportunity to understand how to implement the approach. Two of the five teachers are aware of the TPACK model, a technology integration model that emphasizes the need for technological, pedagogical, and content knowledge to properly infuse technology into the learning process. But when asked how they use such model in designing and delivering their instruction, the teachers are limited to defining what tools they use in the classroom and in the online platform. This simply underscore the idea that while teachers do understand that the mere use of gadgets or software in the classroom does not equate to technological integration, their actual practices reflect significant gaps on how to fully and functionally utilize these tools.

Learning models provide a good guide on how teachers can implement blended learning in their classrooms.

"While we know what to teach, it is becoming a challenge to determine whether a particular material is appropriate for my lesson.”

Teachers asserted that much of the training that they receive emphasizes the change in the kind of students that they have. While this is true, the strategies that they use seem to be inefficient as they still struggle to keep some students engaged in the discussion and other activities.

"Regardless of whether it is in the actual classroom or online, students can be very difficult to be engaged in actually doing the task. In some cases, they would simply find an easy way out like copying a material from the internet without even reading it.”

With the assistance of their colleagues and supervisors, teachers would usually address this problem by revisiting their lesson plans and finding ways by which they can alternatively deliver the instruction.

"The biggest challenge is that almost everyone in the school does not really know how to handle such problem. There are some times when our proposed solutions would work. However, when they do not work, everyone in the school becomes lost and is challenged by how to come up with novel approach. This usually results in lengthy discussions.”

\subsubsection{Sufficient Preparation Time}

Being a relatively new approach for the teachers, designing a blended learning environment for their lessons requires significant amount of preparation. 
"The reality is we have to think of activities, then prepare these activities in various modalities. If we are to follow the concept that blended learning should provide independent learning time for students, then we must carefully design our lessons and even our instructional materials based on the principle. Unfortunately, not all of our students can access these materials because of the lack of internet connection; therefore, we have to ensure that even without the online phase, our students can still have the equal opportunity to master the competencies. It is like creating two learning plans.”

In the current system, teachers are usually given breaks from teaching every semester. However, teachers clamor that such "breaks" are spent on attending meetings or seminars and very few days are left for them to prepare for their actual lessons for the next semester. They also have to use these "breaks" to accomplish forms and reports to be submitted to their supervisors, school heads, and district officers.

"It is more unfortunate if you are assigned to teach a new subject. Most often, you are left with no learning materials to use. The school provides manuals, but the teacher has to prepare worksheets, slides, activity sheets, and other instructional devices. The few weeks before the opening of the classes could have been used for that."

\subsection{Prospects for the Use of Blended Learning}

There is still no definite framework for the implementation of blended learning in many schools. At least for the teachers included in the study, blended learning is limited to the basic definition of combining face-to-face and online instruction. There is a lack of regular blending of these modalities as can be seen in rotation models. Despite this, the positive effects of blended learning as reported in literature [5] [9] [10] [13] have been recognized by students. Therefore, it would be beneficial for schools and teachers to reevaluate their employment of blended learning to maximize its potential.

Teachers and students agree that technical skills must be considered for both groups. Teachers need training to improve their technical skills in manipulating relevant equipment and applications. Students, on the other hand, need to be provided with pre-requisite skills in fulfilling several online requirements. A review of the professional development plan can help identify what particular skills are necessary to be mastered by teachers. This will entail the formulation of a school policy pertinent to the implementation of blended learning. This will ensure that every teacher would implement the suitable blending of modalities. The school can have a survey of the internet connectivity of students at home and the availability of necessary gadgets and equipment. The school can also consider the availability of equipment among teachers so that they could provide the needed support to students.
A well-planned curriculum that considers blended learning approach is key in ensuring pedagogical support is available for both teachers and students. Teachers and students must be part of the planning process to increase accountability in the implementation. Teachers must be given appropriate training on how to seamlessly integrate technology in providing other modalities of teaching for their everyday instruction.

In the age where technological advancement is progressing at an exponential rate, the educational system has no other ways but to anchor itself to the emerging trends to ensure that their graduates are equipped with the industrial skills needed in the workplace. Blended learning does not only afford the independent pacing of learning for students but are also providing them with opportunities to learn beyond the bounds of the classroom. This could be the manifestation of the shifting role of teachers as facilitators rather than sole source of information.

\section{Conclusions}

The present study aimed to explore the experiences of the teachers and students in using blended learning in their classes. By interfacing the perspectives of both teachers and students, a deeper discussion of how schools can support the implementation of blended learning is provided. In the perspective of the students, blended learning may be beneficial if they are properly equipped with the skills and knowledge on how to navigate the various tasks given to them. Among the concerns that they have are (a) the alignment of the face-to-face and online tasks; (b) proper spacing of activities; and (c) lack of consideration for pre-requisite skills. Students can better comply with the tasks for both face-to-face and online instructions which are related to each other. Because of the difficulty of monitoring online activities, students sometimes find themselves working on multiple online tasks while still trying to comply with their classroom requirements. Also, students are sometimes provided with tasks that they do not have the necessary skills to accomplish.

Teachers, on the other hand, reported the lack or inadequacy of technical skills, training for new pedagogy, and sufficient preparation time. Teachers are aware that blended learning requires a specific set of paradigms to be implemented efficiently. Unfortunately, these training remain to be superficial and could not really provide the necessary level of competence for the teachers. Further, the lack of preparation time for the instructional materials for either face-to-face or online instruction is causing them to feel that they do not really maximize the potentials of blended learning.

The findings of this study present challenges that must be addressed by schools in implementing blended learning. The experiences of the teachers and students in this study 
do not dispute the reported relevance and benefits of blended learning. However, for these potentials to be fully realized, sufficient pedagogical support for both teachers and students must be provided. These pedagogical supports can enable the teachers to effectively design a blended learning model appropriate for their classes and students. School heads can look into these findings in planning for possible professional development activities for their teachers that could directly address their concerns.

The study is conducted among schools that may not have a structured blended learning model. Thus, results must be taken with caution as the implementation of blended learning significantly depends on the context of the schools and the surrounding community.

\section{REFERENCES}

[1] Staker, H., \& Horn, M. B. (2012). Classifying K-12 blended learning. Innosight Institute.

[2] Garrison, D. R., \& Kanuka, H. (2004). Blended learning: Uncovering its transformative potential in higher education. The internet and higher education, 7(2), 95-105.

[3] Singh, H. (2003). Building effective blended learning programs. Educational Technology-Saddle Brook Then Englewood Cliffs NJ-, 43(6), 51-54.

[4] Moskal, P., Dziuban, C., \& Hartman, J. (2013). Blended learning: A dangerous idea? The Internet and Higher Education, 18, 15-23.

[5] So, H. J., \& Brush, T. A. (2008). Student perceptions of collaborative learning, social presence and satisfaction in a blended learning environment: Relationships and critical factors. Computers \& education, 51(1), 318-336.

[6] Poon, J. (2013). Blended learning: An institutional approach for enhancing students' learning experiences. Journal of online learning and teaching, 9(2), 271-288.

[7] Lynch, R., \& Dembo, M. (2004). The relationship between self-regulation and online learning in a blended learning context. The International Review of Research in Open and Distributed Learning, 5(2).

[8] George-Walker, L. D., \& Keeffe, M. (2010). Self determined blended learning: a case study of blended learning design. Higher Education Research \& Development, 29(1), 1-13.

[9] Rovai, A. P., \& Jordan, H. (2004). Blended learning and sense of community: A comparative analysis with traditional and fully online graduate courses. The International Review of Research in Open and Distributed Learning, 5(2).

[10] López-Pérez, M. V., Pérez-López, M. C., \& Rodríguez-Ariza, L. (2011). Blended learning in higher education: Students' perceptions and their relation to outcomes. Computers \& education, 56(3), 818-826.
[11] Boyle, T., Bradley, C., Chalk, P., Jones, R., \& Pickard, P. (2003). Using blended learning to improve student success rates in learning to program. Journal of educational Media, 28(2-3), 165-178.

[12] Porter, W. W., Graham, C. R., Spring, K. A., \& Welch, K. R. (2014). Blended learning in higher education: Institutional adoption and implementation. Computers \& Education, 75, 185-195.

[13] Stockwell, B. R., Stockwell, M. S., Cennamo, M., \& Jiang, E. (2015). Blended learning improves science education. Cell, 162(5), 933-936.

[14] Liu, Q., Peng, W., Zhang, F., Hu, R., Li, Y., \& Yan, W. (2016). The effectiveness of blended learning in health professions: systematic review and meta-analysis. Journal of medical Internet research, 18(1), e2.

[15] Kintu, M. J., Zhu, C., \& Kagambe, E. (2017). Blended learning effectiveness: the relationship between student characteristics, design features and outcomes. International Journal of Educational Technology in Higher Education, 14(1), 7.

[16] Bradshaw, C., Atkinson, S., \& Doody, O. (2017). Employing a qualitative description approach in health care research. Global qualitative nursing research, 4, 233339361774228 2. 